\title{
COMUNICAÇÃO
}

\section{QUALIDADE FISIOLÓGICA E PRODUTIVIDADE DE SEMENTES DE FEIJÃO ORIUNDAS DE SEMENTES TRATADAS COM ENRAIZANTE E NUTRIÇÃO MINERAL DAS PLANTAS}

\author{
Physiological quality and yield of bean seeds from the seeds treated \\ with rooter and mineral nutrition plants
}

\author{
José Renato Emiliorelli Evangelista ${ }^{1}$, João Almir Oliveira ${ }^{2}$, Frederico José Evangelista Botelho ${ }^{2}$, \\ Bruno Oliveira Carvalho ${ }^{3}$, Felipe de Lima Vilela ${ }^{3}$, Gustavo Evangelista Oliveira ${ }^{3}$
}

\begin{abstract}
RESUMO
Objetivou-se neste trabalho avaliar os efeitos do enraizante, via tratamento de sementes na qualidade fisiológica das sementes e da adubação foliar associada ao tratamento de sementes com o enraizante, sobre caracteres agronômicos da cultura do feijoeiro. Para o ensaio em campo, sementes da cultivar Pérola foram tratadas com o fungicida Tegram ${ }^{\circledR} \mathrm{em}$ associação com o enraizante Wiser, na dosagem de $200 \mathrm{~mL} / 100 \mathrm{~kg}$ de sementes. A semeadura foi realizada em solo com e sem adubação e após 30 e 60 dias da semeadura foi realizada a aplicação foliar com o produto Fitofos K Plus ${ }^{\circledR}$. Esse ensaio foi constituído de parcelas subdivididas em sistema fatorial 2x2x2 (Adubação foliar, adubação no solo e enraizante) em DBC. Foi avaliada a população aos 21 dias e a produtividade. Para ensaio em laboratório, foram utilizados 5 lotes de sementes da cultivar Pérola tratadas com o fungicida Tegram ${ }^{\circledR}$ e o enraizante Wiser, na dosagem de $200 \mathrm{~mL} / 100 \mathrm{~kg}$ de sementes, sendo esse ensaio constituído de sistema fatorial 5x2 (lotes e enraizante) em DBC. As sementes foram avaliadas pelo teste de germinação, emergência de plântulas em canteiro e em vasos e massa seca da parte aérea. O uso do enraizante reduz a germinação e o vigor de sementes de feijão, já quando associado ao adubo foliar, o enraizante proporcionou um aumento na produtividade na ausência de adubação no solo.
\end{abstract}

Termos para indexação: Phaseolus vulgaris, adubação foliar, emergência, germinação.

\begin{abstract}
The objective of this study was to evaluate the effect of the rooter applied through seed treatment on the physiological quality of seeds and the leaf fertilization associated with the seed treatment with rooter in agronomic traits in the bean culture. For the research in field, seeds of cultivar Perola were treated with the Tegram ${ }^{\circledR}$ fungicide in association with the Wiser rooter in the dosage of $200 \mathrm{~mL} / 100 \mathrm{~kg}$ seeds. Seeds were sown in soil with or without fertilization and after 30 and 60 days of the sowing, the leaf fertilization was made with Fitofos K Plus ${ }^{\circledR}$. This research was constituted of split plot in factorial system $2 \times 2 \times 2$ (leaf fertilization, soil fertilization and rooter) in RBD. It was evaluated the population at 21 days and the productivity. For laboratory research, 5 lots of seeds of Perola cultivar treated with the fungicide Tegram and the Wiser rooter in the dosagem of $200 \mathrm{~mL} / 100 \mathrm{~kg}$ seeds were used, in a factorial system $5 \times 2$ (lots and rooter) in RBD. Seeds were evaluated by germination test, emergency in bed, emergency in vases and shoot dry matter. The use of the rooter reduces germination and vigor of bean seeds and associated with leaf fertilizer, provided an increase in the productivity in the absence of soil fertilization.
\end{abstract}

Index terms: Phaseolus vulgaris, leaf fertilization, emergency, germination.

(Recebido em 8 de janeiro de 2008 e aprovado em 10 de fevereiro de 2010)

O feijoeiro (Phaseolus vulgaris L.) é cultivado no Brasil, praticamente, durante o ano inteiro, sendo a primeira época de cultivo chamada feijão "das águas" responsável por aproximadamente $50 \%$ da área plantada, representando $45 \%$ da produção nacional e com produtividade média de $560 \mathrm{~kg} \mathrm{ha}^{-1}$ (Yokoyama et al., 2000).

Bragantini (1996) e Yokoyama et al. (2000) relataram que, para o aumento da produtividade é essencial a melhoria do nível tecnológico da cultura do feijoeiro, na qual incluise o emprego de sementes de alta qualidade e um bom manejo nutricional da planta. Por outro lado, a adubação foliar e a incorporação de macro e micronutrientes, via tratamento de sementes são algumas alternativas para o aumento da produtividade.

A aplicação de nutrientes via foliar, prática hoje comumente utilizada por produtores de diversas culturas

1Universidade Federal de Lavras/UFLA - Departamento de Agricultura/DAG - Cx. P. 37 - 37200-000 - Lavras, MG - j.renatoevangelista@yahoo.com.br 2Universidade Federal de Lavras/UFLA - Departamento de Agrigultura/DAG - Lavras, MG

${ }^{3}$ Universidade Federal de Lavras/UFLA - Lavras, MG 
como forma de complementação à adubação no solo, é uma prática cultural já adotada, mas os resultados, muitas vezes, não são fundamentados por dados de pesquisas. Segundo Bulisani et al. (1973), é plenamente justificado o prosseguimento dos estudos sobre o assunto, devido à facilidade de aplicação e custo relativamente baixo, mormente se as pulverizações com fertilizante foliar forem associadas a defensivos.

Freire et al. (1980) trabalharam com formas diferentes de aplicação de nutrientes e relataram que a adubação foliar é um meio eficiente para o suprimento de nutrientes para a planta. Em se tratando do fornecimento de macronutrientes, a adubação foliar deve ser considerada como um complemento da adubação do solo e nunca como substitutiva, pois, verifica-se que, para suprir as necessidades da planta é necessário um número maior de pulverizações, o que seria antieconômico. Rezende et al. (2009) observaram aumentos significativos no rendimento de grãos na cultura da soja quando foi realizada a adubação foliar com enxofre em diferentes doses.

Para os micronutrientes, exigidos em pequenas quantidades, a adubação foliar poderá suprir todas as exigências da planta. A eficiência do fornecimento de nutrientes via foliar é geralmente maior que o fornecimento via solo, acarretando economia de fertilizantes (Rosolem, 1987). Lima et al. (1999) trabalhando com Mo, B e Zn via foliar na cultura do feijoeiro, em duas safras (Outono/ inverno e Verão), obteve resultados significativos. A aplicação foliar de Mo elevou o número de vagens por planta, o número de grãos por vagem e o peso médio do grão, resultando em incremento de produtividade da ordem de $40 \%$. Porém, as aplicações foliares de boro e zinco não afetaram de maneira significativa as variáveis estudadas.

A incorporação de microelementos juntamente com o tratamento de sementes é uma técnica comum, pois a uniformidade de distribuição de pequenas doses, que podem ser aplicadas com precisão, é uma das vantagens desse método de aplicação. A eficiência dessa tecnologia já foi comprovada para aplicação de Mo e também de Co em leguminosas, com vista à fixação simbiótica de nitrogênio. Sfredo et al. (1996) obtiveram aumento médio de produção de soja, variando de 18 a 37\%, em relação ao tratamento com inoculante, pela aplicação de vários produtos comerciais multinutrientes via tratamento de sementes, em três locais no estado do Paraná. Os autores atribuíram esses resultados à presença do Mo nesses produtos. Além do Mo e Co, também B, Cu, Mn e Zn já foram aplicados via sementes, muitas vezes com resultados positivos (Ruschell et al., 1970; Mortvedt \& Cox, 1985).
Existem, entretanto, casos em que o tratamento de sementes com micronutrientes não apresenta efeitos positivos na produção. A aplicação de $\mathrm{B}, \mathrm{Cu}, \mathrm{Mo}$ e $\mathrm{Zn}$, via tratamento de sementes, não aumentou a produção de arroz (Barbosa Filho et al., 1983).

$\mathrm{O}$ fósforo $(\mathrm{P})$, que é um macronutriente essencial ao metabolismo das plantas, desempenhando papel importante na transferência de energia da célula, na respiração e na fotossíntese, pode ser aplicado como suplementação à adubação de solo na cultura do feijoeiro por meio da adubação foliar e também via tratamento de sementes. Esse nutriente é também componente estrutural dos ácidos nucléicos de cromossomos, assim como de muitas coenzimas, fosfoproteínas e fosfolipídeos. Desse modo, limitações na disponibilidade de P no início do ciclo vegetativo podem resultar em menor desenvolvimento da planta, mesmo aumentando o suprimento de $\mathrm{P}$ para níveis adequados. $\mathrm{O}$ suprimento adequado de $\mathrm{P}$, diferentemente dos demais nutrientes, é essencial desde os estádios iniciais de crescimento da planta (Grant et al., 2001).

Segundo Fageria et al. (2003), o P na cultura do feijoeiro exerce importância fundamental no aumento da produção de massa seca da parte aérea, aumento do número de vagens e massa de grãos, principais determinantes da produtividade. Contudo, dentre os componentes da produção, o número de vagens por unidade de área é o que mais contribui para o aumento da produtividade do feijoeiro. Oliveira et al. (1987), avaliando cultivares de feijão quanto à eficiência no uso de $\mathrm{P}$, verificaram que o maior retorno de produção de grãos foi obtido aplicando-se doses de 30 e $120 \mathrm{~kg} \mathrm{ha}^{-1}$ de $\mathrm{P}_{2} \mathrm{O}_{5}$. Em condições de casa de vegetação, Fageria (1998) constatou que os genótipos de feijão apresentaram comportamento diferenciado com relação à eficiência de utilização de fósforo.

Objetivou-se, neste trabalho, avaliar os efeitos do enraizante via tratamento de sementes na qualidade fisiológica das sementes e da adubação foliar associada ao tratamento das sementes, com o enraizante sobre caracteres agronômicos da cultura do feijoeiro.

O trabalho foi conduzido no Campo Experimental e no Laboratório de Análise de Sementes do Departamento de Agricultura da Universidade Federal de Lavras (UFLA).

Para instalação do experimento no campo, foram utilizadas sementes de feijão da cultivar Pérola tratadas com o fungicida Tegram ${ }^{\circledR}$, na dosagem de $200 \mathrm{~mL} / 100 \mathrm{~kg}$ de sementes. Junto ao tratamento fungicida foi associado ou não o produto enraizante Wiser, na dosagem recomendada pelo fabricante $(200 \mathrm{~mL} / 100 \mathrm{~kg}$ de sementes $)$.

$\mathrm{O}$ solo foi preparado convencionalmente e a semeadura realizada manualmente, em 25/11/2005 e a 
colheita em 15/02/2006. Cada parcela foi constituída de quatro linhas de $5 \mathrm{~m}$ de comprimento, espaçadas de $0,45 \mathrm{~m}$ entre linhas, com densidade de semeadura de 20 sementes por metro, considerando como área útil as duas linhas centrais. Posteriormente foi realizado desbaste, deixando 15 plantas por metro. Após a determinação da população de plantas aos 21 dias após o plantio, foi realizado o desbaste, deixando 60 plantas por parcela.

Parte da área foi adubada, seguindo as recomendações da Comissão de Fertilidade do Solo do estado de Minas Gerais - CFSEMG (1999) e, em parte, não foi aplicada adubação ao solo. Para a adubação foliar foi utilizado o FITOFOS K PLUS ${ }^{\circledR}$, aplicado aos 30 e aos 60 dias após semeadura.

O manejo de plantas daninhas foi realizado por capinas manuais, objetivando manter a cultura no limpo, e aos 60 dias após a emergência da plântula foi feito o controle de Diabrótica sp. (Brasileirinho), sendo a pulverização feita com pulverizador costal utilizando o inseticida Decis $25 \mathrm{CE}$ na dosagem recomendada pelo fabricante.

Foram avaliadas as seguintes características agronômicas:

População aos 21 dias: 21 dias após o plantio foram contabilizadas as plantas emergidas na parcela experimental. Os dados foram transformados em número de plantas por ha.

Produtividade: a área útil foi colhida manualmente e as plantas secadas ao sol, até atingirem o ponto de debulha, quando foi feita a trilha manual, em seguida foram feitas a limpeza e a pesagem dos grãos. Os dados foram corrigidos para umidade de $13 \%$ e a produtividade foi expressa em $\mathrm{kg} / \mathrm{ha}$.

Para instalação do experimento em laboratório, foram utilizados cinco diferentes lotes de sementes de feijão da cultivar Pérola, tratadas com o fungicida Tegram ${ }^{\circledR}$, na dosagem de $200 \mathrm{~mL} / 100 \mathrm{~kg}$ de sementes. Ao tratamento fungicida foi associado ou não o enraizante Wiser, na quantidade de $200 \mathrm{~mL} / 100 \mathrm{~kg}$ de sementes. Após o tratamento as sementes foram submetidas as seguintes determinações:

Teste de germinação: foi realizado segundo as Regras para Análise de Sementes - RAS (Brasil, 1992), utilizando 200 sementes por tratamento, divididas em quatro repetições de 50 sementes. As mesmas foram semeadas em rolo de papel Germitest, umedecido com água destilada na quantidade de 2,5 vezes o peso do pape seco, e mantidos em germinador à temperatura de $25^{\circ} \mathrm{C}$ por cinco dias, quando foi realizada a avaliação. Os resultados foram expressos em porcentagem de plântulas normais.

Emergência de plântula em canteiro: foram semeadas quatro repetições de 50 sementes por tratamento em canteiro em condição ambiente, sendo irrigados quando necessário. A avaliação foi realizada a partir da emergência das primeiras plântulas até a estabilização e o índice de velocidade de emergência foi determinado segundo fórmula proposta por Maguire (1962).

Emergência de plântula em vasos: em substrato solo + areia na proporção $2: 1$, foram semeadas quatro repetições, sendo cinco sementes por vaso a uma profundidade de 3 $\mathrm{cm}$. Após a emergência das plântulas, em cada vaso foi realizado o desbaste deixando duas plântulas. Aos 40 dias após a semeadura, as plantas foram medidas com auxílio de uma régua, em seguida as plantas foram arrancadas do vaso separando a parte aérea das raízes. A parte aérea das plantas foram colocadas em estufa de circulação de ar até manterem peso constante e posteriormente foram pesadas e os resultados expressos em gramas por planta.

$\mathrm{O}$ experimento em laboratório foi instalado em delineamento inteiramente casualizado (DIC), em sistema fatorial 5x2 (lotes e enraizante). Para o experimento de campo, utilizou-se o delineamento experimental em blocos casualizados em esquema fatorial $2 \times 2 \times 2$ (Adubação foliar, adubação no solo e produto enraizante) com parcela subdividida, avaliando nas parcelas a adubação foliar e nas subparcelas o produto enraizante e adubação no solo e as análises estatísticas para os ensaios foram realizadas, utilizando o programa SISVAR.

Pelos resultados do teste de germinação (Tabela 1), observa-se que não houve diferenças significativas entre lotes, no entanto, quando as sementes foram tratadas com o enraizante ocorreu efeito prejudicial desse sobre a germinação das sementes para os lotes 4 e 5. Esses dois lotes embora não tenham diferido quanto à germinação, provavelmente estavam mais deteriorados ou com algum dano que possa ser causado por toxicidade do produto.

Tabela 1 - Porcentagem de germinação de cinco lotes de sementes de feijão, tratadas ou não com enraizante Wiser. UFLA, Lavras, MG, 2006.

\begin{tabular}{ccc}
\hline \multirow{2}{*}{ Lotes } & \multicolumn{2}{c}{ Enraizante } \\
\cline { 2 - 3 } & Com & Sem \\
\hline 1 & $97,5 \mathrm{Aa}$ & $95 \mathrm{Aa}$ \\
2 & $93,5 \mathrm{Aa}$ & $96 \mathrm{Aa}$ \\
3 & $96,5 \mathrm{Aa}$ & $95,5 \mathrm{Aa}$ \\
4 & $91 \mathrm{Ba}$ & $98,5 \mathrm{Aa}$ \\
5 & $91 \mathrm{Ba}$ & $96,5 \mathrm{Aa}$ \\
\hline
\end{tabular}

Médias seguidas pela mesma letra maiúscula na linha e minúscula na coluna, não diferem estatisticamente entre si pelos Testes de F e Tukey, a 5\% de probabilidade. 
Pelos resultados do índice de velocidade de emergência de plântula em canteiro e massa da matéria seca da parte aérea, houve efeitos significativos apenas para enraizante, verificando que o uso do enraizante Wiser foi prejudicial. Foi observado um menor índice, quando se utilizou o enraizante $(11,72)$ do que quando o mesmo não foi utilizado $(12,39)$, e pela massa da matéria seca da parte aérea das plantas também verificou-se a redução da massa com aplicação do enraizante de 10,82 g para 10,08 g. Esse fato pode ter ocorrido por uma provável toxidez devido ao volume de calda utilizado no tratamento das sementes ou de sua composição química, uma vez que após aplicação nas sementes ocorreu a formação de uma camada de gel ao redor da semente, impossibilitando a secagem adequada para o manuseio. Isso pode ter restringido a passagem de água e oxigênio, retardando a germinação e consequentemente reduzindo o índice e a massa da matéria seca.

Quanto à altura de plantas (Tabela 2), verifica-se que para o lote 1 o enraizante causou redução do tamanho, sendo que esse resultado não foi notado para os demais lotes, porém quando não se utilizou o produto, via tratamento de sementes, o lote 1 apresentou maior altura que os lotes 2 e 5, não diferindo estatisticamente dos demais.

No campo, observou-se a redução significativa do número de plantas por parcela aos 21 dias, quando se utilizou o enraizante $(159,5)$, sendo que, quando não se utilizou o produto o número de plantas por parcela foi de 168,56 em média. No entanto Zucareli et al. (2006), trabalhando com diferentes dosagens de fósforo em feijoeiro, observaram que o aumento das doses favoreceu o estabelecimento da cultura, reduzindo as perdas das plantas durante o ciclo.
Ao avaliar a produtividade (Tabela 3), observou-se que na ausência da adubação do solo, o enraizante Wiser juntamente com a adubação foliar proporcionaram um aumento da produtividade de mais de $200 \mathrm{~kg} / \mathrm{ha}$. Oliveira et al. (1987), ao avaliarem cultivares de feijão quanto à eficiência no uso de fósforo, verificaram que maior produção de grãos foi obtida quando se fez a adubação fosfatada.

Tabela 2 - Altura de plantas ( $\mathrm{cm}$ ) obtidas a partir de cinco lotes de sementes de feijão, tratadas ou não com enraizante Wiser. UFLA, Lavras, MG, 2006.

\begin{tabular}{ccc}
\hline \multirow{2}{*}{ Lotes } & \multicolumn{2}{c}{ Enraizante } \\
\cline { 2 - 3 } & Com & Sem \\
\hline 1 & $21,92 \mathrm{Ba}$ & $26,61 \mathrm{Aa}$ \\
2 & $21,94 \mathrm{Aa}$ & $20,88 \mathrm{Ab}$ \\
3 & $23,92 \mathrm{Aa}$ & $23,06 \mathrm{Aab}$ \\
4 & $23,56 \mathrm{Aa}$ & $22,50 \mathrm{Aab}$ \\
5 & $23,44 \mathrm{Aa}$ & $21,88 \mathrm{Ab}$ \\
\hline
\end{tabular}

Médias seguidas pela mesma letra maiúscula na linha e minúscula na coluna, não diferem estatisticamente entre si pelos Testes de F e Tukey, a $5 \%$ de probabilidade.

Resultados semelhantes foram obtidos por Rezende et al. (2005), que testando aplicações do elemento $\mathrm{P}$ em diferentes estádios de desenvolvimento de plantas de soja obtiveram incrementos em produtividade de até $16 \%$.

O uso de produtos enraizantes reduz a germinação e o vigor de sementes de feijão.

A associação do enraizante Wiser, com a adubação foliar com Fitofos K Plus promovem o aumento de produtividade na ausência de adubação no solo.

Tabela 3 - Resultados médios de produtividade $(\mathrm{kg} / \mathrm{ha}$ ) de plantas de feijão, provenientes de sementes tratadas ou não com produto enraizante e submetidas ou não à adubação foliar e adubação no solo. UFLA, Lavras, MG, 2006.

\begin{tabular}{ccccc}
\hline & \multicolumn{4}{c}{ Enraizante } \\
\cline { 2 - 5 } Adubação no Solo & \multicolumn{3}{c}{ Com } & \multicolumn{2}{c}{ Sem } \\
\cline { 2 - 5 } & \multicolumn{2}{c}{ Adubo Foliar } & Com & Sem \\
\cline { 2 - 5 } & $1361,07 \mathrm{Aa}$ & $1328,44 \mathrm{Aa}$ & $1316,37 \mathrm{Aa}$ & $1237,51 \mathrm{Aa}$ \\
Com & $1506,87 \mathrm{Aa}$ & $1210,05 \mathrm{Ab}$ & $1285,8 \mathrm{Ba}$ & $1361,04 \mathrm{Aa}$ \\
\hline Sem & &
\end{tabular}

Médias seguidas pela mesma letra maiúscula na linha e minúscula na coluna, não diferem estatisticamente entre si pelo Teste de $\mathrm{F}$, a $5 \%$ de probabilidade. 


\section{REFERÊNCIAS BIBLIOGRÁFICAS}

BARBOSA FILHO, M.P.; FAGERIA, N.K.; FONSECA, J.R. Tratamento de sementes de arroz com micronutrientes sobre o rendimento e qualidade dos grãos. Pesquisa Agropecuária Brasileira, Brasília, v.18, n.3, p.219-222, mar. 1983.

BRAGANTINI, C. Produção de sementes. In: ARAUJO, R.S.; RAVA, C.A.; STONE, L.F.; ZIMMERMANN, M.J. (Eds.). Cultura do feijoeiro comum no Brasil.

Piracicaba: POTAFOS, 1996. p.639-667.

BRASIL. Ministério da Agricultura e Reforma Agrária. Regras para análise de sementes. Brasília, 1992. 365p.

BULISANI, E.A.; ALMEIDA, L.A.D.; DEMATTÊ, J.D. Observações preliminares sobre adubação foliar em feijoeiro (Phaseolus vulgaris L.) Bragantia, v.32, p.13-17, 1973.

\section{COMISSÃO DE FERTILIDADE DO SOLO DO} ESTADO DE MINAS GERAIS. Recomendações para o uso de corretivos e fertilizantes em Minas Gerais: $\mathbf{5}^{\mathbf{a}}$ Aproximação. Viçosa, MG, 1999. 359p.

FAGERIA, N. K. Eficiência de uso de fósforo pelos genótipos de feijão. Revista Brasileira de Engenharia Agrícola e Ambiental, Campina Grande, v.2, n.2, p.128131, 1998.

FAGERIA, N.K.; BARBOSA FILHO, M.P.; STONE, L.F. Resposta do feijoeiro a adubação fosfatada. Piracicaba: Potafós, 2003. (Informações Agronômicas, 102).

FREIRE, F.M.; MONNERAT, P.H.; MARTINS FILHO, C.A.S. Nutrição mineral e adubação do tomateiro. Informe Agropecuário, Belo Horizonte, v.6, p.13-20, 1980.

GRANT, C.A.; PLATEN, D.N.; TOMAZIEWICZ, D.J.; SHEPPARD, S.C. A importância do fósforo no desenvolvimento inicial da planta. Informações Agronômicas, Piracicaba, n.95, p.1-5, set. 2001.

LIMA, S.F. et al. Resposta do feijoeiro à adubação foliar de boro, molibdênio e zinco. Ciência e Agrotecnologia, Lavras, v.23, n.2, p.462-467, 1999.
MAGUIRE, J.D. Spped og germination aid in selection and evaluation for seedling and vigour. Crop Science, Madison, v.2, n.2, p.176-177, 1962.

MORTVEDT, J.J.; COX, F.R. Production, marketing and use of calcium, magnesium and micronutrient fertilizers. In: ENGELSTAD, O.P. (Ed.). Fertilizer technology and use. 3.ed. Madison: Soil Science Society of America, 1985. p.455-481.

OLIVEIRA, I.P.; THUNG, M.; KLUTHCOUSKI, J.; AIDAR, H.; CARVALHO, J.R. Avaliação de cultivares de feijão quanto a eficiência no uso de fósforo. Pesquisa Agropecuária Brasileira, Brasília, v.22, n.1, p.39-45, 1987.

REZENDE, P.M.; CARVALHO, E.R.; SANTOS, J.P.; ANDRADE, M.J.B.; ALCANTARA, H.P. Enxofre aplicado via foliar na cultura da soja [Glycine max (L.) Merrill]. Ciência e Agrotecnologia, Lavras, v.33, n.5, p.1255-1259, 2009.

ROSOLEM, C.A. Nutrição e adubação do feijoeiro. Piracicaba: Potafos, 1987. (Boletim técnico, 8).

RUSCHEL, A.P.; ROCHA, A.C.M.; PENTEADO, A.F. Efeito do boro e do molibdênio aplicados a diferentes revestimentos de semente de feijão (Phaseolus vulgaris). Pesquisa Agropecuária Brasileira, Rio de Janeiro, v.5, p.49-52, 1970.

SFREDO, G.J.; BORKERT, C.M.; CASTRO, C. de. Efeito de micronutrientes sobre a produção de soja em três solos do Estado do Paraná. Informações Agronômicas, Piracicaba, n.75, p.2-3, set. 1996.

YOKOYAMA, L.P.; WETZEL, C.T.; VIEIRA, E.H.N.; PEREIRA, G.V. Sementes de feijão: produção, uso e comercialização. In: VIEIRA, E.H.N.; RAVA, C.A. (Eds.). Sementes de feijão: produção e tecnologia. Santo Antônio de Goiás: Embrapa, 2000. p.249-270.

ZUCARELI, C.; BARREIRO, A.P.; NAKAGAWA, J.; CAVARIANI, C. Phosphorus fertilization, production components, productivity and seed physiological quality in common beans seeds. Revista brasileira de sementes, Pelotas, v.28, n.1, p.9-15, 2006. 